Vol. 8(4), pp. 219-233, April 2014

DOI: $10.5897 / A J$ EST2014.1644

Article Number. ADBE7CE44341

ISSN 1996-0794

Copyright (c) 2014

Author(s) retain the copyright of this a rticle

http://www.academicjoumals.org/AJ EST
African Journal of Environmental Science and Technology

\title{
Household-scale environmental health in the Ezulwini Valley, Swaziland
}

\author{
James D. Proctor*, Ben Rathbun, Erin Scheibe and Samantha Shafer \\ Environmental Studies Program-MSC 62, Lewis \& Clark College, 0615 SW Palatine Hill Road, Portland, OR 97219 \\ USA.
}

Received 02 January, 2014; Accepted 2 April, 2014

\begin{abstract}
An environmental health assessment of $\mathbf{2 1 0}$ households located in four communities in the Ezulwini Valley, Swaziland, is summarized. The assessment focused on household-scale environmental health in the context of four key resource sectors: drinking water, energy, solid waste and human waste, with availability and perceived adequacy considered for each sector. The survey was administered in the field by small teams of students alongside Swazi community members, utilizing a snowball sampling strategy with stratification by economic class. Electronic administration via mobile devices assisted in geolocating records, minimizing entry error and rapidly compiling results for daily review and analysis. Results indicate challenges in household access to basic resources and resource impacts, even in this relatively developed part of Swaziland; these results varied considerably by community and economic class, and were only somewhat comparable to previous national-scale assessments. In a larger context, international efforts toward improving household-scale environmental health conditions (e.g., via related UN Millennium Development Goals) are laudable, yet these results corroborate other research suggesting that progress can be difficult to measure, and is decidedly uneven by household location and socioeconomic status.
\end{abstract}

Key words: Swaziland, environmental health, water, sanitation, solid waste, fuelwood, Millennium Development Goals (MDGs).

\section{INTRODUCTION}

Situating global environmental health

The field of environmental health is as broad as our many needs for well-being and safe surroundings. According to the World Health Organization (WHO), environmental health "...addresses all the physical, chemical and biological factors external to a person, and all the related factors impacting behaviours. It encompasses the assessment and control of those environmental factors that can potentially affect health" (www.who.int/topics/environmental_health). The most recent WHO report (2013a) launches with a foreword citing the eight UN Millennium Development Goals (MDGs) for 2015, in which environment and health are

${ }^{\star}$ Corresponding author. E-mail: jproctor@Iclark.edu. Tel: 503.768.7707 or 503.768.7620.

Author(s) agree that this article remain permanently open access under the terms of the Creative Commons Attribution License 4.0 International License 
central to at least four (www.un.org/millenniumgoals).

As with most global health statistics, however, environmental health is a key axis of differentiation between socioeconomic classes. For instance, WHO/UNICEF Joint Monitoring Programme for Water Supply and Sanitation (JMP) statistics for 2011 indicate that $67 \%$ of the population from World Bank low income group countries have access to improved drinking water sources, as compared to $99 \%$ in high income group countries, and only $37 \%$ from low income countries have access to improved sanitation as compared to $100 \%$ from high income countries (for further details, see WHO Global Health Observatory Data Repository, apps.who.int/gho/data; all statistics from 2011). One would expect that inequities in environmental health are present at the sub-country scale as well, given evidence suggesting marked disparities in other health indicators among the most and least wealthy members of a wide range of countries (WHO, 2013b, 143ff). Eradication of these disparities has been a major goal of the UN MDGs, yet the empirical question remains as to whether progress in global environmental health is moving quickly among poor people of the world; at least some published reviews of progress toward MDGs suggest otherwise (Poku and Whitman, 2011; Usua et al., 2012; Fehling et al., 2013).

\section{Environmental health in Africa}

Many people living in Africa face particular challenges relative to the rest of the world. The most recent World Health Organization statistical summary (2013b) launches by comparing regions of the world in progress toward MDG goals relative to 1990, and Africa's improvement in under-five mortality rates, as one indicator of health conditions, is higher than many other parts of the world, with an annual rate of decline close to $2 \%$ (p. 13). Yet absolute rates in maternal mortality, tuberculosis, HIVIAIDS and access to improved drinking water and sanitation are still considerably worse in Africa than in other parts of the world (pp. 14-17). These statistics suggest good progress over the last several decades, offset by continued struggles in securing adequate standards of general and environmental health (Gabay, 2011; Groenewald, 2011; Mukonka et al., 2014), especially in an equitable manner across socioeconomic class (Kangalawe et al., 2008; Yanda and William, 2010).

In the last five years, a great deal of attention has been paid to environmental health conditions in Africa. The proceedings of one major conference including 52 African country delegations and held in Libreville, Gabon in August 2008 launches by stating that "Africa continues to face the 'traditional' challenges of poor access to safe drinking water, hygiene and sanitation. Yet the continent must now also deal with new and emerging challenges, including the effects of climate change on health, accelerated urbanization and indoor and outdoor air pollution" (WHO, 2009a, 7). A frequently cited statistic in the proceedings is the estimate that nearly one-quarter of all deaths in Africa in 2002 were attributable to "environmental risk factors" (WHO, 2009a, 23; cf. Ogunseitan, 2007). The conference resulted in the Libreville Declaration on Health and Environment in Africa (WHO, 2009b), suggesting widespread commitment to improving environmental health conditions on the continent. The conference was followed by a smaller implementation meeting (WHO, 2009c). Overall, WHO pursued a wide range of public and environmental health initiatives in Africa in the latter part of the first decade of the 21st century (WHO, 2010).

\section{The status of Swaziland}

Swaziland is a small landlocked country in southern Africa, with a 2011 population of approximately 1.2 million inhabitants. According to World Bank statistics (data.worldbank.org), its general economic conditions are somewhat better than those of its peers: for instance, its 2011 gross national per capita income was estimated at US\$2,830, over twice the average for developing countries in sub-Saharan Africa (US\$1,248). Yet its health struggles are considerable: Swaziland has the highest HIV infection rate of any country in the world. According to the World Health Organization, in 2011 190,000 people or $15.8 \%$ of the overall population were HIV positive, including $26 \%$ of the population aged 15 to 49. This has contributed in large part to a life expectancy at birth of only 49 years, and at least 75,000 orphans due to parent death from AIDS (WHO Global Health Observatory Data Repository, apps.who.int/gho/data, all statistics from 2011).

The general environmental status of Swaziland has been summarized in a recent comprehensive assessment by the Swaziland Environment Authority (2012), focusing on five themes: land, water, atmosphere, biodiversity and human development. In the context of human health, the report concludes that "Swaziland faces many challenges in the human health sector among which limited capacity in terms of human and financial resources is one, and weak information systems particularly in relation to monitoring and evaluation of different priority health programmes is another" (p. 258). To compare this status with other countries in Africa, WHO health statistics estimate that $28 \%$ of Swaziland's population did not have access to improved drinking water sources in 2011 , and $43 \%$ did not have improved sanitation (WHO, 2013b, 33-4), placing Swaziland in the 46th and 79th percentiles, respectively, among African countries (with higher percentiles being better status).

A more detailed health assessment was done via the 2010 Multiple Indicator Cluster Survey (MICS), administered in conjunction with UNICEF, and involving 
Table 1. Selected Swaziland Multiple Indicator Cluster Survey (MICS) results, in percentage $(n \approx 4800$ households).

\begin{tabular}{lccc}
\hline Item & Urban & Rural & Overall \\
\hline Improved water & 91 & 60 & 67 \\
Water treatment & 24 & 14 & 15 \\
Improved sanitation & 94 & 73 & 78 \\
\hline
\end{tabular}

Table 2. Percent household access to improved water in Swaziland by wealth quintile ( 5 = richest; 1 = poorest).

\begin{tabular}{lc}
\hline Wealth index quintile & $\begin{array}{c}\text { Improved } \\
\text { water access }\end{array}$ \\
\hline 5 & 92 \\
4 & 77 \\
3 & 66 \\
2 & 60 \\
1 & 41 \\
\hline
\end{tabular}

nearly 5000 Swazi households (Central Statistical Office and UNICEF, 2011). The UNICEF MICS instrument focuses on key MDGs, in particular those related to human health. As suggested in Table 1, the MICS found that $67 \%$ of the overall population had access to improved water sources and $78 \%$ had access to improved sanitation facilities. Though the MICS improved water access result is in rough agreement with the WHO figure provided above, the marked disparity between the MICS improved sanitation result of $78 \%$ and the WHO figure of $57 \%$ may suggest the need for greater methodological agreement. Table 1 also suggests that only $15 \%$ of the population had access to treated water sources, a much smaller proportion than those with access to "improved" sources, suggesting a key disparity to be discussed further below. A comparison between the overall population with access to improved water and those from rural vs. urban areas (Table 1) and poor vs. rich wealth quintiles (Table 2) demonstrates significant geographic and economic class variation masked in the overall percentage, as suggested in the JMP statistics above.

Further evidence on the state of Swaziland's rural environmental health can be gained from a series of annual assessments produced by the Swaziland Vulnerability Assessment Committee (2011, 2012). The SVAC reports include statistics on basic household resources such as water and energy necessary to secure livelihoods: for instance, in $201131 \%$ of rural respondents indicated an environmental hazard (solid or liquid waste, or liquid or sewage discharges) near their water source (SVAC, 2011, 48), and in 2012, 82\% of rural households relied on fuelwood for cooking, vs. only $18 \%$ using electricity (SVAC, 2012, 13).

Overall, however, a more comprehensive picture of household access to safe resources, and impacts on these resources, has not been developed for Swaziland. By way of terminology, a household in Swaziland comprises an extended family unit dwelling on a homestead, which typically includes a number of adjacent dwelling and storage structures. Historically, Swazis generally dwelled in a more dispersed fashion on homesteads rather than in a nucleated fashion in villages, and some vestiges of this cultural past remain even in more densely settled parts of the country.

In light of the key role played by basic resources such as water and energy for household well-being, potential health effects of these resources on households (e.g., waterborne disease or indoor air pollution via fuelwood burning), and potential impacts of households on these resources (e.g., contamination by solid or human waste), this study focuses on household-scale environmental health in the context of four key resource sectors: drinking water, energy, solid waste and human waste. These resources are commonly considered in householdscale assessments in Africa (Joséphine et al., 2008; Oyelola and Babatunde, 2008; Ewodo et al., 2009; Awe et al., 2011; Mughogho and Kosamu, 2012), though they are less commonly brought together to present a more comprehensive view.

\section{MATERIALS AND METHODS}

\section{Study site: Ezulwini Valley}

The Ezulwini Valley (literally, Valley of Heaven) is classified in SVAC reports as part of a peri-urban corridor stretching between Mbabane and Manzini, the two largest urban areas in Swaziland (Figure 1). The Ezulwini Valley has great significance to Swazis, with the Parliament, National Archives, Somhlolo National Stadium, and major traditional sites located here. Additionally, Ezulwini has been a site of considerable commercial development, with numerous high-end resorts and a major shopping center. Based on this traditional and commercial significance, the Ezulwini Valley would appear to be superior to many other locations in Swaziland in terms of basic household resource needs. As a study site, then, Ezulwini is not "representative" of Swaziland (an impossibility at any rate, given geographic and economic class variability in basic resources as noted above); rather, it suggests how households are faring in a relatively developed part of Swaziland outside of Mbabane and Manzini.

Our connection to the Ezulwini Valley involved students from Lewis \& Clark College in Portland, Oregon volunteering May through July 2013 in local community neighborhood care points, or NCPs, as part of an overseas program. Neighborhood care points were created in Swaziland in response to the HIV-AIDS crisis, as a means of providing basic food, health, and educational services to vulnerable populations, in particular orphans and vulnerable children (U.S. Fund for UNICEF, 2011). The original NCPs were created following a severe drought in 2003; there are now over 1500 distributed across Swaziland, providing a variety of services and exhibiting a wide range of structural improvements (NERCHA, 2011). 


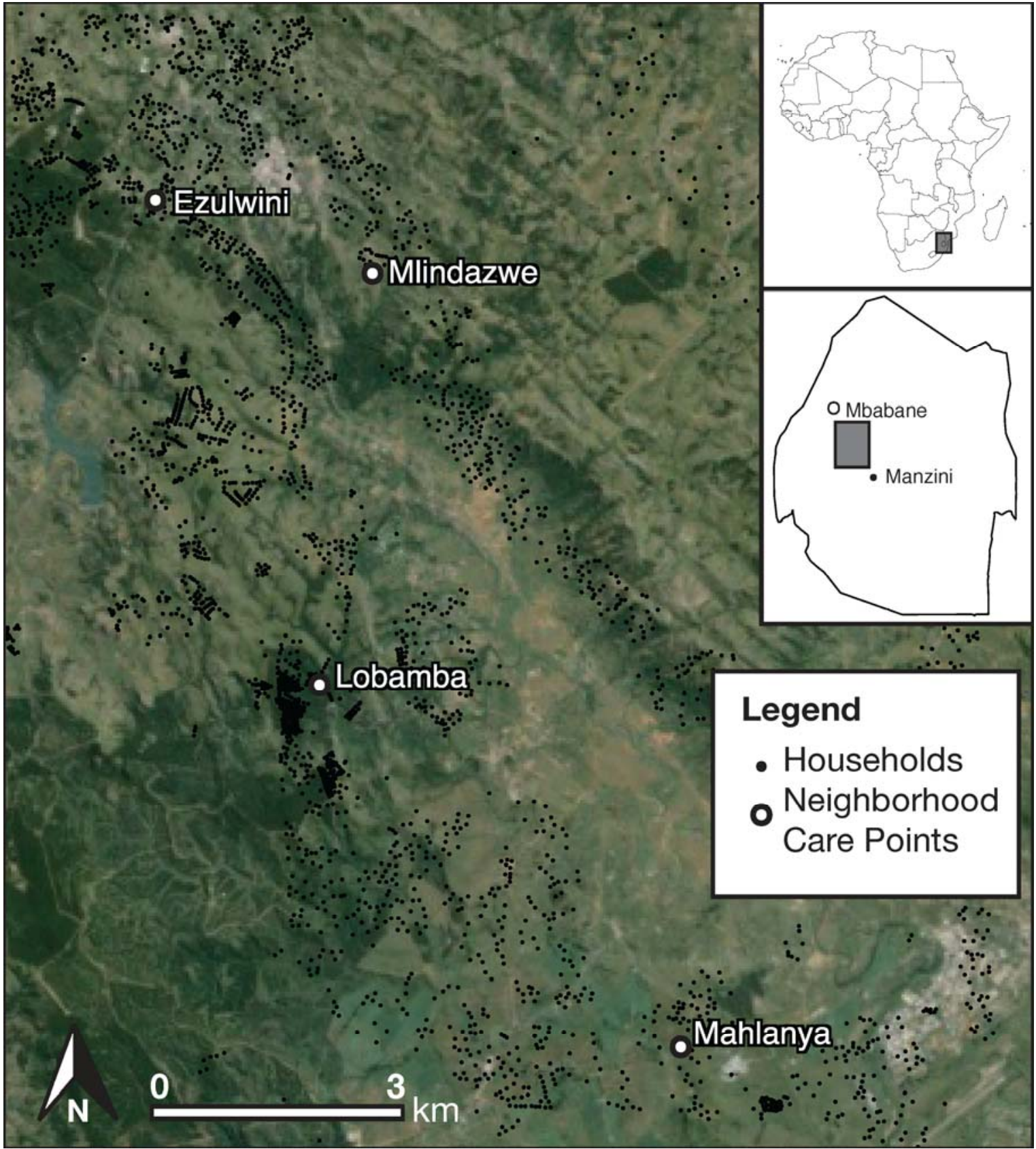

Figure 1. Location map of Ezulwini Valley study site in Swaziland, with four neighborhood care points and surrounding communities included in environmental health assessment.

Students worked in partnership with All Out Africa (www.alloutafrica.com), an organization based in the Ezulwini Valley that places volunteers in a number of local NCPs, which they also support via building assistance, educational materials, and other services. Students volunteered in four NCPs and conducted our environmental health assessment among households in the surrounding communities (Figure 1). Of these four NCPs, Ezulwini and Lobamba NCP are found in relatively densely settled periurban areas, whereas Mlindazwe and Mahlanya NCP are found in less densely settled areas with more rural characteristics. All four NCPs we selected are relatively close together, lying within a $12 \mathrm{~km}$ span of the Ezulwini Valley.

\section{Research question}

Our research question was "What is the condition and perception of water, energy and solid/human waste among households in communities surrounding four NCPs in the Ezulwini Valley?" In addition, we planned to compare results by community and economic level, and with country-scale Swaziland data. As is evident in these questions we were interested not only in the current state of these resources and resource impacts, but in how they were perceived and prioritized among the Swazis who lived in these communities, as any attempt to improve environmental health conditions must be grounded in knowledge of both. We also 
Table 3. Environmental health assessment sections.

\begin{tabular}{|c|c|}
\hline Section & Content \\
\hline Pre- Survey Information & $\begin{array}{l}\text { Survey location, reference number } \\
\text { Economic class surrogates } \\
\text { Respondent age/gender }\end{array}$ \\
\hline Household General & $\begin{array}{l}\text { Settlement duration } \\
\text { Number of minor/adults } \\
\text { Most important issues }\end{array}$ \\
\hline Drinking Water & $\begin{array}{l}\text { Sources } \\
\text { Treatment } \\
\text { Quantitative/qualitative adequacy } \\
\text { Notes/recommendations }\end{array}$ \\
\hline Household Energy & $\begin{array}{l}\text { General energy sources } \\
\text { Cooking energy sources } \\
\text { Fuel wood cooking method/location } \\
\text { Cooking energy adequacy } \\
\text { Notes/recommendations }\end{array}$ \\
\hline Solid Waste & $\begin{array}{l}\text { Disposal locations } \\
\text { Community adequacy } \\
\text { Notes/recommendations }\end{array}$ \\
\hline Human Waste & $\begin{array}{l}\text { Sanitation facility locations } \\
\text { Community adequacy } \\
\text { Notes/recommendations }\end{array}$ \\
\hline
\end{tabular}

anticipated that differences would arise across communities and economic class, and in spite of the relatively unrepresentative nature of the Ezulwini Valley as a study location we wanted to compare our results with related data collected for Swaziland.

\section{Survey design}

The survey instrument was constructed in consultation with related assessments. Input and translation assistance to SiSwati was provided via key Swazi contacts (including Swazi students attending Lewis \& Clark College). The survey was pretested in the field to ensure straightforward and consistent administration. We used actual photos of households in the Ezulwini Valley to train teams in calibrating the low/medium/high economic class categories, thus aiding consistency across community survey teams.

The instrument included six major sections, with primary survey items noted for each in Table 3 . The overall flow of the survey was intended to begin with background information collected by survey administrators without prompting respondents, e.g., economic class surrogates and respondent approximate age and gender. It further solicited general household information, followed by each of the four priority resource sectors, starting with drinking water as a straightforward, recognized sector and ending with solid and human waste as more sensitive sectors. A general discussion of respondents' most important community issues was included prior to resource-specific sections to gauge the larger significance of these resources. For all sectors, respondent perception/prioritization was elicited via perceived adequacy items using a three-point scale (inadequate/somewhat adequate/adequate), where adequacy involved the household scale for drinking water (which included both qualitative and quantitative adequacy, that is, sufficient purity and volume) and energy, and the community scale for solid and human waste given the potential for cross-household impacts. The overall survey took between 10 and 30 min to administer per household.

\section{Survey administration and analysis}

Following student NCP volunteer work in the mornings, the environmental health assessment was conducted after the NCPs closed at midday, in teams of 1-3 students together with 1-4 Swazis (including Swazi Lewis \& Clark students and NCP community members). Our goal was to survey approximately 50 households in each of the four communities, a decision based primarily on afternoon time available in each community, though we did oversample in Lobamba given its larger population, ending up with an overall sample of 210 households (Table 4). Due to technical and practical challenges in surveying a random sample of households, we adopted a snowball sampling strategy, starting with the households of contacts (e.g., cooks or participating youth) in the NCPs, then moving on to neighbors or other contacts. Given our interest in the effects of differing levels of wealth on householdscale environmental health, we informally stratified our community 
Table 4. Neighborhood care point (NCP) communities and households.

\begin{tabular}{|c|c|c|c|c|c|}
\hline Household & Ezulwini & i Lobamba & Mahlanya & Mlindazwe & Total \\
\hline $\begin{array}{l}\text { Households within } 0.5 \\
\mathrm{~km} \text { radius of NCP }\end{array}$ & 201 & 401 & 66 & 72 & 740 \\
\hline Households surveyed & 50 & 72 & 51 & 37 & 210 \\
\hline
\end{tabular}

samples by economic class surrogates, primarily structural improvements and amenities (e.g., wall/roof materials, structure size, presence of satellite dish antenna). These sampling and quota decisions mean that our survey is not necessarily representative of these four communities in the Ezulwini Valley, but it does suggest some important characteristics of the households we surveyed, as well as similarities and differences by community and economic class.

The survey was administered using iPad Mini mobile devices running a survey app called Fulcrum (www.fulcrumapp.com). The iPads and Fulcrum app offered a number of advantages, including (a) concurrent administration via survey downloading to multiple devices, followed by uploading of data at the end of each day; (b) automatic geolocation of households, (c) minimization of entry error via response lists, branching logic and required questions; and (d) accumulation of data onto the Fulcrum site for ready monitoring and downloading. We were also able to provide daily updates and reminders directly on the app. The iPads provided community benefits in addition to survey administration: for instance, our students used them with NCP children during their volunteer time, and took (and printed for distribution) photos of NCP and community members upon request.

A small team of students reviewed data at the end of each day to check for entry error, geolocation error, and other potential problems as well as sample coverage. During the first few days of administering the final survey, these data review meetings proved invaluable in monitoring progress and making team-specific recommendations as well. Additional teams did follow-up reconnaissance of community water and fuelwood sources to determine quality. Water sources were tested for total and fecal coliform and inspected visually for probability of surface runoff contamination; fuelwood sources were assayed for extent, major species and reproduction rate.

Data from the household surveys were downloaded from the Fulcrum website in spreadsheet format, then recoded as necessary for descriptive statistical analysis; text responses were summarized to provide better interpretation of numerical results. Data were also uploaded in shapefile format to QGIS, an open-source GIS and mapping program, to discover spatial patterns. Analysis results were shared with Ezulwini Valley community members and Swaziland government officials in a variety of public events.

\section{RESULTS}

\section{Drinking water}

Selected drinking water results are shown in Figure 2 and Table 5. As noted above, the concept of "improved" drinking water, which has been central to MDG and Swaziland rural development goals, is arguably vague, as most assessments consider as "improved" any piped water irrespective of source protection or treatment. We thus adopted a more restrictive definition of "improved" in our survey. In brief, we distinguished in our survey between piped water (drinking water obtained via a piped distribution system, whether a community or private tap) and improved water (water considered safe to drink as a result of source protection or treatment); whereas virtually all improved water is piped, not all piped water is improved (safe to drink).

Table 5 thus lists the percentage of households in each community and overall with access to piped water, improved water and springs and streams (which are potentially unsafe due to surface runoff contamination), as well as those households who treated their drinking water (e.g., by boiling or adding bleach). Since some piped water was deemed improved (safe to drink), and some unimproved spring/stream sources were piped, the top three rows add up to more than $100 \%$.

Overall, fully $70 \%$ of the 210 households we surveyed had access to piped water sources, which is understandable given the relatively developed nature of the Ezulwini Valley. Yet only $37 \%$ had access to what we determined as improved (safe to drink) sources, many $(32 \%)$ regularly fetched drinking water from springs or streams, and only $9 \%$ did any form of household treatment. These results alone are highly important: nearly two out of three surveyed households in one of the most developed parts of the country regularly access unsafe drinking water sources, and less than one in ten regularly purifies their drinking water. Additionally, access time to water sources was significant even for this relatively developed area, with a mean roundtrip time of $50 \mathrm{~min}$. Figure 2 and Table 9 suggest important differences between the four surveyed communities in their access to safe drinking water. The two more urban communities, Ezulwini and Lobamba, had relatively high proportions of households supplied by piped water, in contrast to the more rural community of Mahlanya, which relied heavily on springs and streams. Mlindazwe, the other community of a more rural nature, also had a high proportion of piped water, but in all cases these distribution systems relied on unimproved and untreated water sources. Access to improved water sources ranged from nil in Mlindazwe to $79 \%$ in Lobamba, the site of a former royal village and an important traditional and administrative center.

Perhaps surprisingly, access to piped water predictably was found to increase beyond the low economic class sector, but access to improved (safe to drink) water 


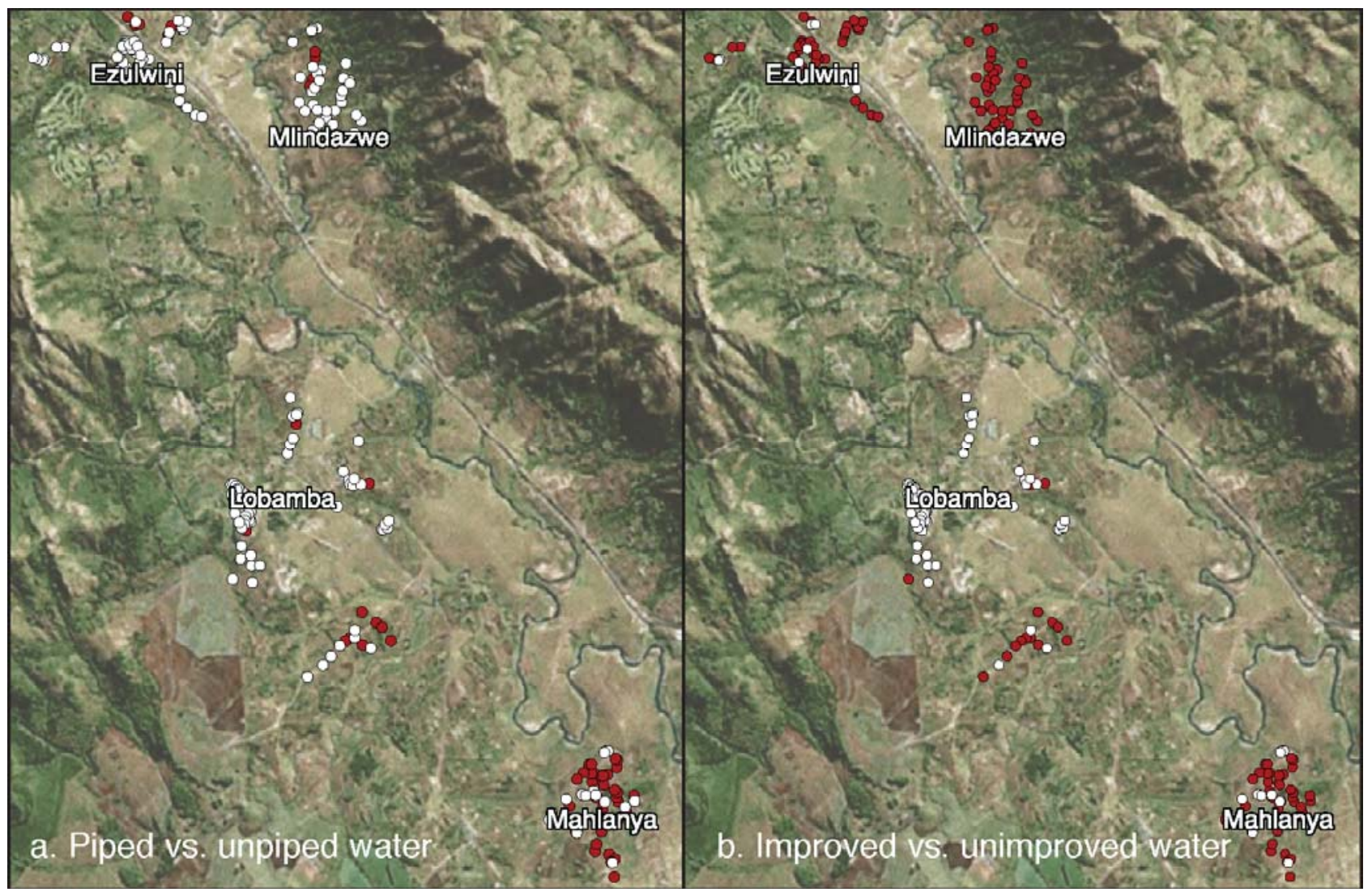

Figure 2. Distribution of households using (a) piped (white) versus unpiped domestic water and (b) improved (white) versus unimproved domestic water sources.

Table 5. Water source type and water treatment practice (percent households surveyed) by community.

\begin{tabular}{lccccc}
\hline Item & Ezulwini & Lobamba & Mahlanya & Mlindazwe & Overall \\
\hline Piped water & 86 & 76 & 31 & 89 & 70 \\
Improved water & 20 & 79 & 20 & 0 & 37 \\
Springs/streams & 18 & 21 & 73 & 16 & 32 \\
Any household treatment & 14 & 3 & 10 & 13 & 9 \\
\hline
\end{tabular}

actually decreased as economic class increased. How could this be? To be sure, a small number of wealthier households utilized their own private deep wells (boreholes), but most relied on piped systems shared with their communities, which as noted above were not consistently improved. One possible explanation for this anomalous result is that economic class may be a surrogate here for particular communities, given the vastly disparate community-scale results: in Lobamba, where improved water sources are commonly used, only one household in eight was rated upper economic class, whereas in Mlindazwe, for instance, where no surveyed households used improved water, almost seven out of eight were rated medium or high economic class.

\section{Energy}

Figure 3 and Table 6 present results of the household energy portion of our environmental health assessment. As could be expected in this relatively developed part of Swaziland, fully $71 \%$ of surveyed households utilized electricity as a general energy source (usually for lighting and outlets). In contrast, only $32 \%$ of households used electricity for cooking, a function of its perceived high cost relative to other options. The most common source of cooking energy was harvested wood, which roughly onehalf of all households used; some respondents also purchased fuelwood from nearby vendors, who generally transport wood from other parts of the country to the 


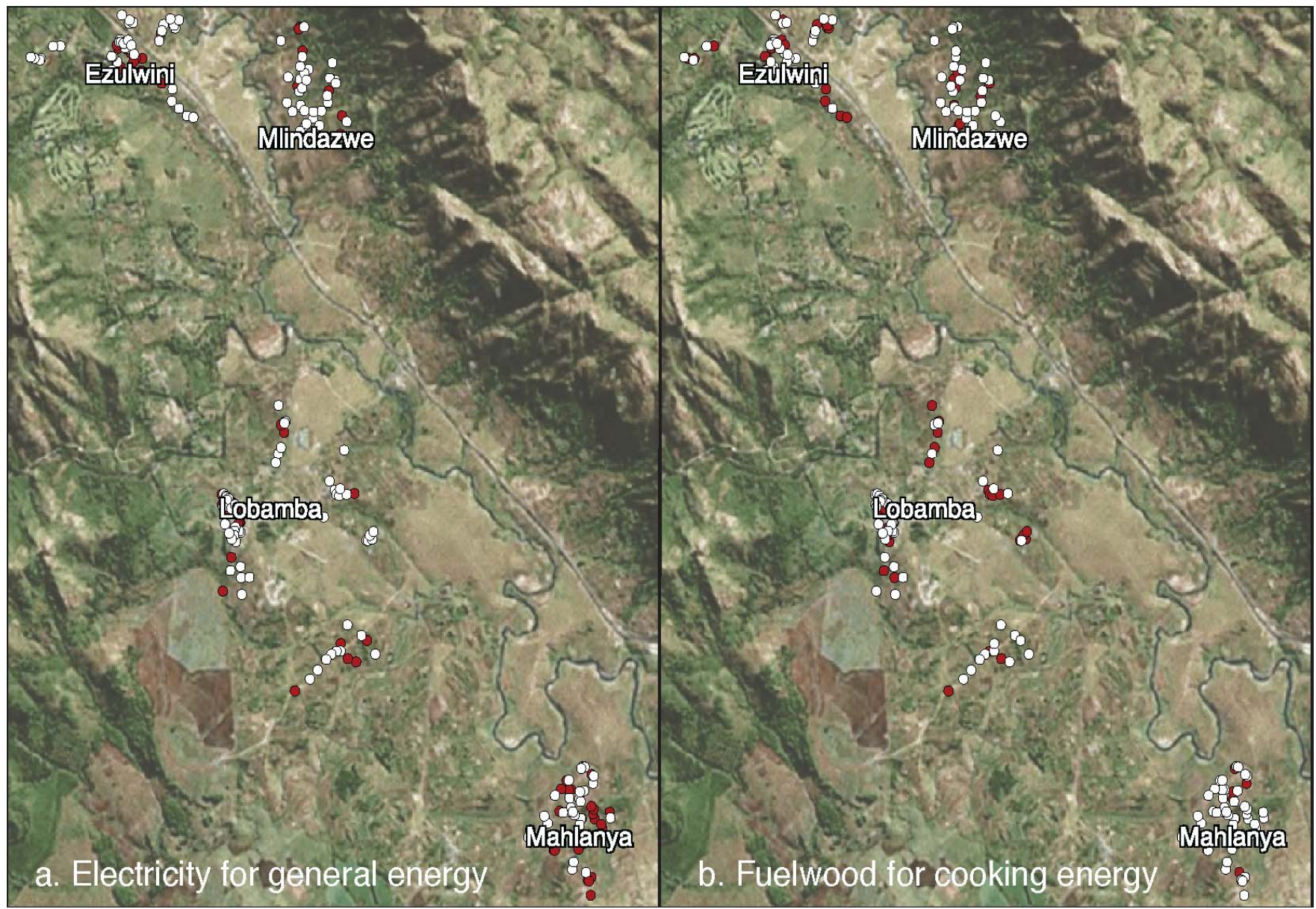

Figure 3. Distribution of households using (a) electricity (white) for general energy needs and (b) fuelwood (white) for cooking energy needs.

Table 6. Energy source type (percent households surveyed) by community.

\begin{tabular}{lccccc}
\hline Energy Source & Ezulwini & Lobamba & Mahlanya & Mlindazwe & Overall \\
\hline Electricity (general) & 76 & 72 & 59 & 81 & 71 \\
Electricity (cooking) & 50 & 28 & 14 & 43 & 32 \\
Compressed gas & 34 & 17 & 6 & 0 & 15 \\
Fuelwood (harvested) & 42 & 46 & 53 & 60 & 49 \\
Fuelwood (purchased) & 24 & 19 & 43 & 22 & 27 \\
\hline
\end{tabular}

Ezulwini Valley given high demand relative to supply. Though fuelwood is traditionally used for cooking in Swaziland, this high percentage of harvested wood in the Ezulwini Valley is surprising given the relatively high settlement density as indicated in Figure 1 . In all, $71 \%$ of households used harvested or purchased wood for cooking, exactly equal to the proportion that used electricity for general (non-cooking) energy needs.

A comparison of energy use by community suggests quite large differences in use of electricity for cooking (ranging from $14 \%$ in rural Mahlanya to $50 \%$ in peri-urban Ezulwini), presumably due in part to readily availability of fuelwood nearby for harvest or purchase. Trends in energy use by economic class (Table 9) are marked: high economic class households used electricity far more frequently for cooking than medium and low economic class households (e.g., roughly seven in ten among high vs. one in ten among low economic class households), and far less harvested wood. Evidently, decisions as to cooking energy are based on a tradeoff of cost verse labor, 


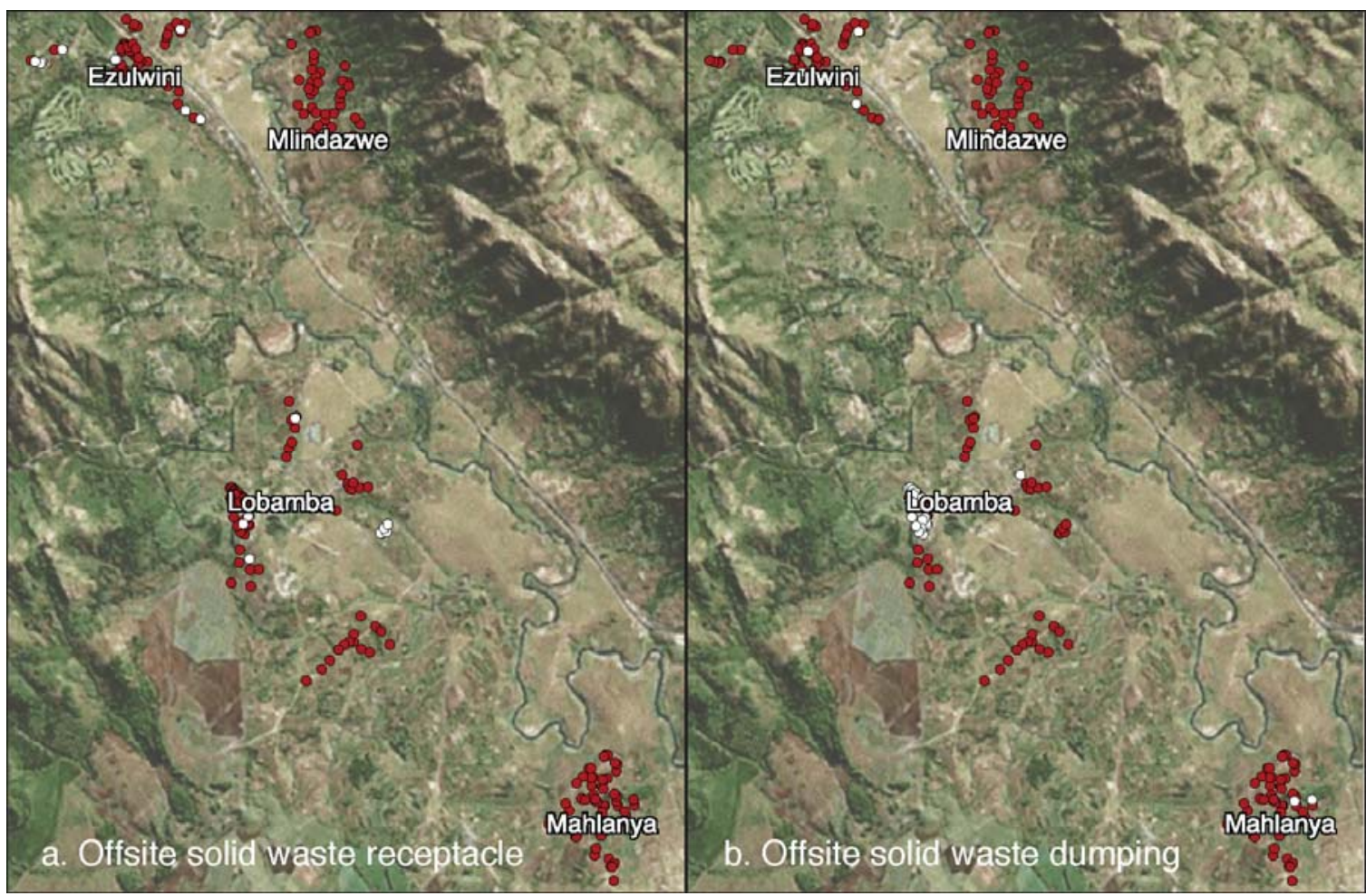

Figure 4. Distribution of households using (a) offsite solid waste receptacle (white) and (b) dumping solid waste offsite (white) in non-designated location.

Table 7. Solid waste disposal method (percent households surveyed) by community.

\begin{tabular}{llllll}
\hline Disposal method Ezulwini & Lobamba & Mahlanya & Mlindazwe & Overall \\
\hline Burn onsite & 62 & 51 & 94 & 95 & 72 \\
Bury onsite & 60 & 13 & 0 & 5 & 20 \\
Offsite receptacle & 18 & 11 & 0 & 0 & 8 \\
Offsite dumping & 8 & 26 & 4 & 3 & 12 \\
\hline
\end{tabular}

as fetching fuelwood can take a great deal of time $(2.8 \mathrm{~h}$ average roundtrip among reporting households) but communal fuelwood reserves are free.

This heavy reliance on fuelwood for cooking via openair stoves, which are common in Swaziland, results in the well documented environmental health problem of indoor air pollution, for which sub-Saharan Africa is particularly afflicted (Legros et al., 2009). These results suggest that indoor air pollution is widespread even in relatively developed parts of Swaziland such as the Ezulwini Valley, and especially so among low economic class households, and among women who do almost all the cooking in a typical Swazi household. Similar to the relatively low proportion of households that purify their drinking water, however, the ubiquity of this indoor air pollution problem may render it difficult to successfully address.

\section{Solid waste}

The relation between households and their surrounding communities differs in the context of waste: though household drinking water and energy supply options depend on community-scale infrastructure in the Ezulwini Valley, solid and human waste decisions made by households generally have a cumulative impact on their surrounding communities. The household results for waste, then, should be considered at the scale of potential community as well as household impacts.

Figure 4 and Table 7 summarize selected solid waste survey results: overall, by far the most common method of dealing with solid waste was for households to burn or bury their waste onsite (in the immediate vicinity of their dwelling structures), but one in eight dumped their waste offsite (in a non-designated location vs. a landfill). The 


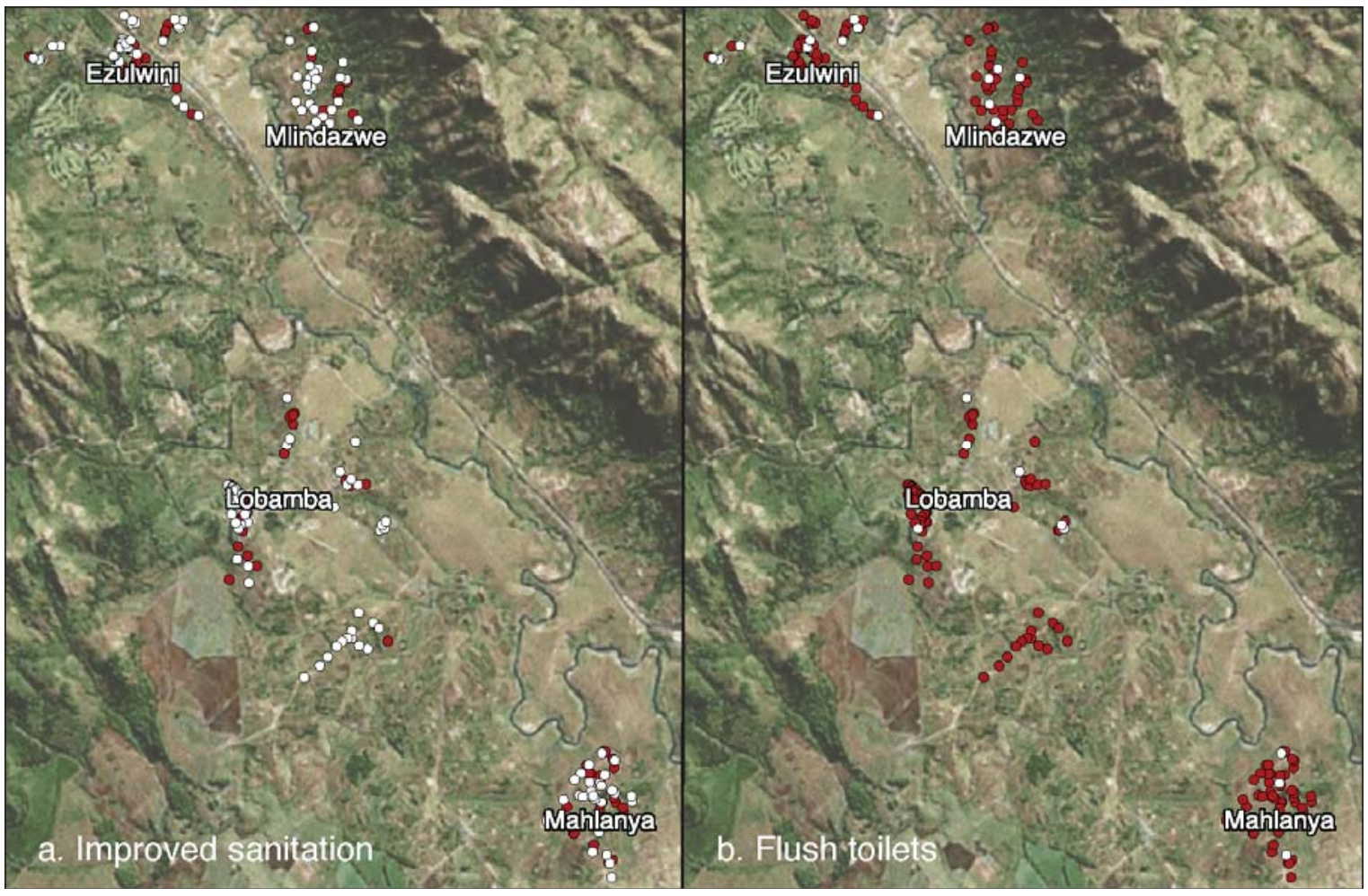

Figure 5. Distribution of households using (a) improved sanitation (white), and (b) flush toilets (white).

Table 8. Human waste disposal method (percent households surveyed) by community.

\begin{tabular}{lccccc}
\hline Disposal method & Ezulwini & Lobamba & Mahlanya & Mlindazwe & Overall \\
\hline Overall improved sanitation & 70 & 67 & 61 & 78 & 68 \\
Flush toilet & 22 & 8 & 6 & 14 & 12 \\
Flush toilet & 54 & 54 & 61 & 76 & 60 \\
Improved latrine & 28 & 19 & 35 & 19 & 25 \\
\hline
\end{tabular}

Ezulwini Town Council maintains a set of solid waste collection receptacles in Ezulwini, with some receptacles in Lobamba as well; for the most part, however, these do not seem to be frequently used, and they are not available in the more rural communities of Mahlanya and Mlindazwe.

A comparison by community reveals, for instance, the stark conditions of peri-urban Lobamba, where crowded homesteads and a lack of collection receptacles have resulted in over one in four households dumping their waste offsite in non-designated locations. The accumulation of solid waste was clearly evident in these parts of Lobamba as well, increasing potential for disease transmission, especially among children who frequently walked or played near affected areas. Economic class seems to play a role as well (Table 9), with higher economic class households using offsite receptacles far more and dumping offsite far less.

\section{Human waste}

Globally, progress in access to sanitation has generally lagged behind provision of water supply, for a variety of political and other reasons (Rosemarin et al., 2008). This larger pattern may not be evident in the Ezulwini Valley: as shown in the human waste survey results in Figure 5 and Table 8. Overall, over two in three surveyed households $(68 \%)$ used improved sanitation facilities for disposal of human waste, in contrast to only $37 \%$ having access to improved (safe to drink) water. These sanitation facilities are generally an improved pit latrine on the homestead (60 percent), though a small proportion (12 percent) of homesteads had flush toilets. Additionally, a full one-quarter of households used latrines that respondents or surveyors deemed unimproved (e.g., without a concrete slab or outdoors).

Comparison by community and economic level reveals 
Table 9. Selected resource results (percent households surveyed) by economic level.

\begin{tabular}{lcccc}
\hline Item & Low economy & Medium economy & High economy & Overall \\
\hline Piped water & 52 & 78 & 78 & 70 \\
Improved water & 42 & 38 & 22 & 37 \\
Electricity (general) & 39 & 81 & 97 & 71 \\
Wood (harvested) & 61 & 49 & 28 & 49 \\
Offsite receptacle & 3 & 7 & 19 & 8 \\
Offsite dumping & 18 & 12 & 6 & 12 \\
Overall improved sanitation & 48 & 74 & 83 & 68 \\
Flush toilet & 2 & 7 & 44 & 12 \\
\hline
\end{tabular}

some patterns in human waste disposal. Community results were generally consistent, with some communityspecific differences: for instance, Ezulwini had a higher proportion of flush toilets $(22 \%)$, in part connected to a community sewer scheme; and more Mahlanya households $(35 \%)$ used unimproved latrines, perhaps in part due to the more rural nature of this community. Differences by economic level (Table 9) are more marked, with higher economic class households reporting much higher use of improved sanitation facilities $(83 \%$ high vs. $48 \%$ low economic class). This difference is understandably even greater in the use of flush toilets ( $44 \%$ high vs. $2 \%$ low economic class). The generally strong performance of Ezulwini Valley homesteads in their use of improved sanitation, therefore, masks important differences by economic class.

\section{Perceived adequacy}

The results above reflect reported reality in the context of four key resources, all with environmental health implications, essential to household well-being in the Ezulwini Valley. To successfully address issues related to these four resources, empirical data on household perceptions of resource adequacy can help us understand the priorities of surveyed communities.

Figure 6 and Table 10 summarize these results, on a Likert-type scale, we devised ranging from 1 (low reported adequacy) to 3 (high reported adequacy). Overall, respondents rated water quality the most adequate (2.6 average), and sources of cooking energy the least (1.9 average). In comparison to the results above, respondents seemed more concerned about adequate drinking water quantity (2.3) than quality (2.6), even though our results indicate relatively few households have access to safe drinking sources. This may suggest challenges in gaining community support for improving drinking water quality if quantitative shortages are not also prioritized. The overall results also suggest that initiatives to address cooking energy challenges may receive strong community support.

Community comparisons summarized in Table 10 suggest considerable variance in perceptions of solid waste disposal adequacy, with the more peri-urban areas of Ezulwini and Lobamba perhaps understandably reporting much poorer adequacy than the more rural areas of Mahlanya and Mlindazwe. A similar difference between peri-urban and more rural communities was found with respect to human waste, and some variance was found in perceived cooking energy adequacy, though likely as a function of fuelwood availability. Water quantity and quality displayed less variance between communities.

When comparing adequacy by economic class (Table 11), the general pattern is one of the lower perceived adequacy among lower economic groups; for instance, perceived cooking energy adequacy ranged from an average of 1.5 among low economic class households to 2.4 among high economic class households, a possible function of the differing energy utilization patterns summarized above. This pattern is particular evident in perceived solid and human waste disposal adequacy, suggesting that lower economic class households may be disproportionately impacted. Less difference is evident in perceived quantitative and qualitative water adequacy.

\section{DISCUSSION}

\section{Summary of results}

A synthesis of the survey results above suggests clear overall patterns, as well as important differences across the four surveyed communities and three economic classes. Given that the Ezulwini Valley is one of the most developed areas in Swaziland, it is unsurprising that over two out of three surveyed households utilize piped drinking water, yet far more surprising that only slightly more than one out of three utilize water from protected or treated sources- a result that proved highly community specific. Access to safe drinking water would be a major environmental health priority, then, in this location; yet the perceived adequacy results summarized above remind us that drinking water quality alone is not the most important priority in these communities. 


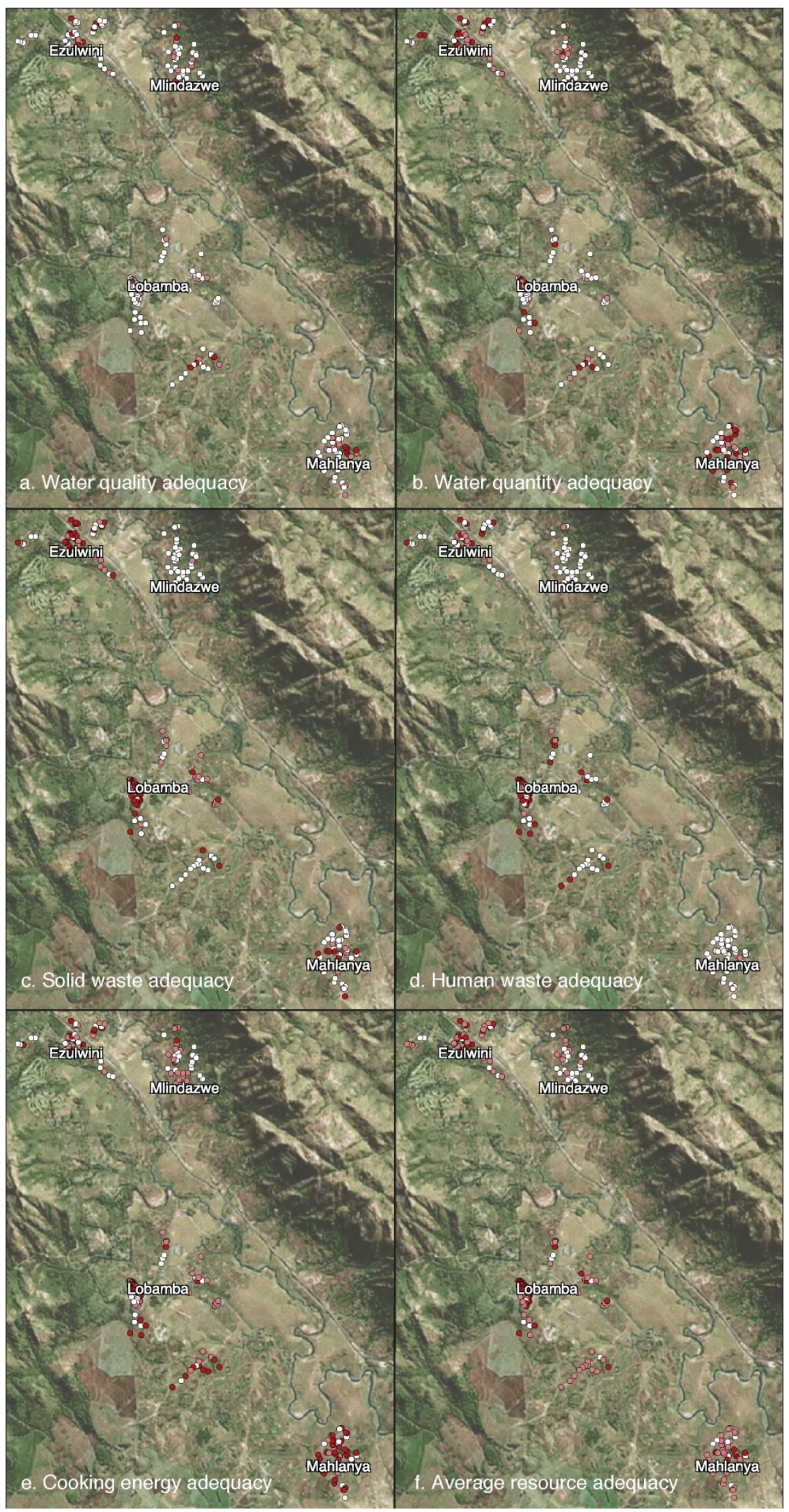

Figure 6. Perceived resource adequacy (white = adequate; red = inadequate) for (a) drinking water quality, (b) drinking water quantity, (c) solid waste, (d) human waste, (e) cooking energy and (f) overall average. 
Table 10. Resource adequacy comparison by community ( $1=$ inadequate; $3=$ adequate $)$.

\begin{tabular}{lccccc}
\hline Resource sector & Ezulwini & Lobamba & Mahlanya & Mlindazwe & Overall \\
\hline Water (quantity) & 2 & 2.5 & 2.1 & 2.6 & 2.3 \\
Water (quality) & 2.6 & 2.8 & 2.5 & 2.6 & 2.6 \\
Cooking energy & 2.1 & 1.8 & 1.5 & 2.4 & 1.9 \\
Solid waste & 1.7 & 1.9 & 2.6 & 3 & 2.2 \\
Human waste & 2.2 & 2 & 3 & 3 & 2.4 \\
\hline
\end{tabular}

Table 11. Resource adequacy comparison by economic level ( $1=$ inadequate; $3=$ adequate).

\begin{tabular}{lcccc}
\hline Resource sector & Low economy & Medium economy & High economy & Overall \\
\hline Water (quantity) & 2.0 & 2.4 & 2.3 & 2.3 \\
Water (quality) & 2.5 & 2.7 & 2.8 & 2.6 \\
Cooking energy & 1.5 & 2.0 & 2.4 & 1.9 \\
Solid waste & 2.0 & 2.2 & 2.6 & 2.2 \\
Human waste & 2.3 & 2.5 & 2.7 & 2.4 \\
\hline
\end{tabular}

A similar disparity is evident in overall household energy results, where over two out of three surveyed households have access to electricity, yet less than one in three use electricity for cooking- in this case, a result that varied significantly according to household economic class. From an indoor air pollution standpoint, and given the increasingly dense settlement (thus fuelwood demand) in the Ezulwini Valley, results from this important resource sector are unacceptable as well. In contrast to drinking water quality, however, there appears to be strong community prioritization of the need to address cooking energy challenges.

Solid and human waste disposal in surveyed communities of the Ezulwini Valley differs in part as a function of community type, where relatively dense periurban areas understandably struggle more with waste than do the more rural communities. Overall, relatively little attention has been devoted to solid waste disposal, and the vast majority of households fend for themselves, though perceived adequacy results suggest strong potential support for improved solid waste disposal in more peri-urban communities. Much more attention has gone to human waste, an even greater environmental health concern: here, over two in three surveyed households utilize improved sanitation facilities, though results differ significantly by household economic class.

\section{Comparison of Ezulwini Valley and Swaziland}

In comparing results from the Ezulwini Valley with the rest of Swaziland, recall the country-scale WHO and UNICEF-sponsored results above, where $67-72 \%$ of the country was reported to have access to improved (piped) water, and $57-78 \%$ was reported to have access to improved sanitation facilities. Relative to these estimates, the Ezulwini Valley is not significantly ahead of nor behind the national average- a relatively surprising result, given the Ezulwini Valley is one of the most developed areas in Swaziland. Households in the Ezulwini Valley do, however, utilize relatively more electricity and less fuelwood for cooking than in the country as a whole. Yet geographic and economic class differences in the Ezulwini Valley appear to be reproduced in the nationalscale picture as well; the overall statistics at both the scale of this area and Swaziland thus apparently mask important differences by location and wealth.

\section{Larger implications}

The prominent role of environmental health in our most important development agendas, such as the UN Millennium Development Goals, is heartening. Yet, the above results from one of the most developed regions in Swaziland are sobering, as the status of drinking water, cooking energy and solid and human waste disposal reveals continued challenges for many households in the area. Indeed, simply assessing progress toward these important MDGs is methodologically challenging: in the key case of drinking water, our study reveals that relatively few "improved" sources may be safe for drinking. More accurately ascertaining progress toward ensuring safe drinking water for all is thus a far more demanding task, and may reveal even poorer overall performance, than efforts to date have suggested. Globally, this disparity between "safe" and "improved" drinking water sources has been recognized by the WHO/UNICEF Joint Monitoring Programme for Water Supply and Sanitation, which is planning a post-2015 
(post-MDG) initiative focusing on evidence-based drinking water, sanitation, and hygiene assessment (WHO 2013b, 19). Additional research tends to corroborate the inadequacy of the MDG definition to ensure provision of truly safe drinking water (Lenton et al., 2008, Dar and Khan, 2011; Clasen, 2012; Sambu and Tarhule, 2013).

Our survey also suggests that overall results mean relatively little in the context of specific communities and socioeconomic classes. We selected four communities located quite close to each other, yet overall householdscale patterns were in many ways unique to each (with the exception of differences between peri-urban and more rural communities). Some enjoy good treated water schemes; some have better fuelwood resources; some worry less about waste. Effectively improving environmental health at the scale of household resource access and impacts, therefore, can only be done by gathering information on, and paying close attention to, community-specific needs and desires.

The additional layer of economic class is a critical one, perhaps no more striking than in the Ezulwini Valley, where among the most wealthy and many poorer households in Swaziland dwell in relatively close proximity. As suggested at the outset, however, this reality is not limited to the Ezulwini Valley nor Swaziland: in the context of urbanizing areas, for instance, "...the health impacts of the most serious problems are largely confined to lower-income groups....It is common for the residential areas of middle- and upper-income groups...to receive good quality water supplies, sewers, drains, electricity supplies and regular services to remove solid waste while $30 \%$ or more of the city population on the poorer residential areas receive little or nothing" (Hardoy et al., 2001).

Household-scale environmental health thus continues to be a challenge in our world, certainly more so among the poor, and with specific needs and priorities among particular communities; though the MDGs have contributed toward improvement, there is a long way to go, and the post-MDG scenario following 2015 is anything but clear (Poku and Whitman, 2011; Vandemoortele, 2011; Usua et al., 2012; Van Norren, 2012; Nayyar, 2013; Kesavan and Swaminathan, 2014). This study of the Ezulwini Valley, the Valley of Heaven, should remind us that there are households located even in relatively developed parts of the world that still face these challenges on a daily basis. Continued attention to fine-scaled data gathering and sharing, as was our survey's intent, may help these areas better identify their needs and desires as they move closer toward creating environments that are safe and healthy for their inhabitants.

\section{Conflict of Interests}

The author(s) have not declared any conflict of interests.

\section{ACKNOWLEDGEMENTS}

We acknowledge the Swaziland Environment Authority and All Out Africa in supporting our Ezulwini Valley environmental health assessment, all Lewis \& Clark students who participated in the assessment, Ezulwini Valley community members, and Swaziland government officials who provided key assistance. We also acknowledge the generosity of The Andrew Mellon Foundation in supporting development of the Swaziland overseas program and our broader situated environmental research approach. Finally, we acknowledge the input of anonymous reviewers, whose comments contributed to improvements of the manuscript.

\section{REFERENCES}

Awe F, Osadebe CO, Imoagene E, Fashina AY, Eniola TS, Adeleke EO (2011). Assessment of rural households' objectives for gathering nontimber forest products (NTFPs) in Kogi State, Nigeria. Afr. J. Environ. Sci. Technol. 5(2):143-148.

Central Statistical Office and UNICEF (2011). Multiple indicator cluster survey 2010. Central Statistical Office and UNICEF, Mbabane, Swaziland.

Clasen TF (2012). Millennium Development Goals water target claim exaggerates achievement: Editorial. Trop. Med. Int. Health 17(10):1178-1180. doi:10.1111/j.1365-3156.2012.03052.x

Dar OA, Khan MS (2011). Millennium development goals and the water target: details, definitions and debate: Millennium development goals and the water target. Trop. Med. Int. Health 16(5):540-544. doi:10.1111/j.1365-3156.2011.02736.x

Ewodo MG, Ekwelgen C, Ntep F, Ekodeck GE (2009). Impact of urbanisation on the Mingosso watershed in the Yaounde periurban zone. Afr. J. Environ. Sci. Technol. 3(10): 272-285. Retrieved from http://www.ajol.info/index.php/ajest/article/download/56255/44700

Fehling M, Nelson BD, Venkatapuram S (2013). Limitations of the Millennium Development Goals: a literature review. Glob. Public Health 8(10):1109-1122. doi:10.1080/17441692.2013.845676

Gabay C (2011). Consenting to "Heaven": The Millennium Development Goals, Neo-liberal Governance and Global Civil Society in Malawi. Globalizations 8(4):487-501. doi:10.1080/14747731.2011.585852

Groenewald L (2011). Progress towards Millennium Development Goals? Strategies for housing and informal settlement in Gauteng, South Africa. Dev. South. Afr. 28(5):641-651. doi:10.1080/0376835X.2011.623912

Hardoy JE, Mitlin D, Satterthwaite D (2001). Environmental problems in an urbanizing world: Finding solutions for cities in Africa, Asia, and Latin America. Earthscan Publications, London.

Joséphine N, Véronique KKB, Luc SN, Georges E, Awah TM (2008). Water supply, sanitation and health risks in Douala, Cameroon. Afr. J. Environ. Sci. Technol. 2(12):422-429.

Kangalawe RY, Liwenga ET, Kabumbuli R, Walingo MK (2008). Livelihood diversification and implications on poverty and environment in the Lake Victoria Basin. Afr. J. Environ. Sci. Technol. 2(10):272-281.

Kesavan PC, Swaminathan MS (2014). From Millennium Development Goals to sustainable development solutions. Curr. Sci. (00113891), 106(4): 495-496.

Legros G, Havet I, Bruce N, Bonjour S (2009). The energy access situation in developing countries. United Nations Development Programme, New York, N.Y.

Lenton R, Lewis K, Wright AM (2008). Water, Sanitation and the Millennium Development Goals. J. Int. Aff. 61(2):247-258.

Mughogho BUG, Kosamu IBM (2012). Water supply arrangements in developing countries: A case study of Blantyre City, Malawi. Afr. J. Environ. Sci. Technol. 6(2): 94-103. 
Mukonka VM, Malumo S, Kalesha P, Nambao M, Mwale R, Mwinga K et al. (2014). Holding a country countdown to 2015 conference on Millennium Development Goals (MDGs) - the Zambian experience. BMC Public Health 14(1):1-7. doi:10.1186/1471-2458-14-60

Nayyar D (2013). The Millennium Development Goals Beyond 2015: Old Frameworks and New Constructs. J. Hum. Dev. Capabilities 14(3):371-392. doi:10.1080/19452829.2013.764853

NERCHA (2011). Mapping of KaGogo centers and neighborhood care points in Swaziland-final report. National Emergency Response Council on HIV and AIDS, Mbabane, July 21.

Ogunseitan O (2007). Top Ten Environmental Priorities for Africa. Afr. J. Environ. Sci. Technol. 1(2). Retrieved from http://www.academicjournals.org/article/article1380104409_Editorial $\% 20(1)$.pdf

Oyelola OT, Babatunde Al (2008). Characterization of domestic and market solid wastes at source in Lagos metropolis, Lagos, Nigeria. Afr. J. Environ. Sci. Technol. 3(12): 430-437. Retrieved from http://www.academicjournals.org/article/article1380186107_Oyelola\% 20and\%20Babatunde.pdf

Poku N, Whitman J (2011). The Millennium Development Goals: challenges, prospects and opportunities. Third World Q. 32(1):3-8. doi:10.1080/01436597.2011.543808

Rosemarin A, Ekane N, Caldwell I, Kvarnström E, McConville J, Ruben C, Fogde Ml (2008). Pathways for sustainable sanitation: achieving the millennium development goals. IWA Publishing, Stockholm.

Sambu DK, Tarhule A (2013). Progress of water service providers in meeting millennium development goals in Kenya. Afr. Geogr. Rev. 32(2):105-124. doi:10.1080/19376812.2013.790643

Swaziland Environment Authority (2012). Swaziland's state of environment report 2012. Swaziland Environment Authority, Mbabane, October 23.

Swaziland Vulnerability Assessment Committee (2011). Annual vulnerability assessment \& analysis report 2011. Swaziland Vulnerability Assessment Committee, Mbabane, Swaziland.

Swaziland Vulnerability Assessment Committee (2012). Annual vulnerability assessment \& analysis report 2012. Swaziland Vulnerability Assessment Committee, Mbabane, Swaziland.

U.S. Fund for UNICEF (2011). Caring for orphaned and vulnerable children in Swaziland. Every Child 3:4-5.
Usua N, Sado A, Nwachukwu F (2012). Rethinking the millennium development goals: ensuring development through communication and participation. Int. J. Acad. Res. 4(6):176-181. doi:10.7813/20754124.2012/4-6/B.27

Van Norren DE (2012). The Wheel of Development: the Millennium Development Goals as a communication and development tool. Third World Q. 33(5):825-836. doi:10.1080/01436597.2012.684499

Vandemoortele $\mathrm{J}$ (2011). If not the Millennium Development Goals, then $\begin{array}{llll}\text { what? } & \text { Third } & \text { World } & \text { 32(1):9-25 }\end{array}$ doi:10.1080/01436597.2011.543809

World Health Organization (2009a). Healthy security through healthy environments: Proceedings of the first interministerial conference on health and environment in Africa, Libreville, Gabon 26-29 August 2008. World Health Organization, Libreville, Gabon.

World Health Organization (2009b). Libreville declaration on health and environment in Africa, Libreville, 29 August 2008. World Health Organization, Libreville, Gabon.

World Health Organization (2009c). Meeting of partners on the implementation of the Libreville declaration on health and environment in Africa: The roadmap to support the implementation of the Libreville Declaration on Health and Environment in Africa (20092010), Windhoek, Namibia, 25-27 February 2009. World Health Organization and United Nations Environment Programme, Windhoek, Namibia.

World Health Organization (WHO) (2010). Public health and environment in the African region: Report on the work of WHO (20082009). World Health Organization, Brazzaville, Congo.

World Health Organization (WHO) (2013a). The world health report 2013: Research for universal health coverage. World Health Organization, Geneva, Switzerland.

World Health Organization (2013b). World health statistics 2013. World Health Organization, Geneva, Switzerland.

Yanda PZ, William C (2010). Livelihoods diversifications and implications on food security and poverty levels in the Maasai plains: The case of Simanjiro district, Northern Tanzania. Afr. J. Environ. Sci. Technol. 4(3): 154-166. Retrieved from http://www.ajol.info/index.php/ajest/article/view/56347 